\title{
First-Principles Calculations of Point Defect Formation and Anion Diffusion Mechanisms in the Oxyhydride $\mathrm{Ba}_{2} \mathrm{ScHO}_{3}$
}

\author{
Akihide Kuwabara $^{\mathrm{a}}$, Fumitake Takeiri ${ }^{\mathrm{b}, \mathrm{c}}$, Haq Nawaz ${ }^{\mathrm{b}, \mathrm{c}}$, and Genki Kobayashi ${ }^{\mathrm{b}, \mathrm{c}}$ \\ ${ }^{a}$ Nanostructures Research Laboratory, Japan Fine Ceramics Center, 2-4-1 Mutsuno, Atsuta, Nagoya \\ 456-8587, Japan \\ b Department of Materials Molecular Science, Institute for Molecular Science, 38 Nishigonaka, \\ Myodaiji, Okazaki, Aichi 444-8585, Japan \\ ${ }^{c}$ SOKENDAI (The Graduate University for Advanced Studies), 38 Nishigonaka, Myodaiji, Okazaki, \\ Aichi 444-8585, Japan
}

\begin{abstract}
Hydride ion conductors are expected to have applications as a new type of solid electrolyte in electrochemical devices utilizing hydrogen. $\mathrm{La}_{2-x-y S r x+y} \mathrm{LiH}_{1-x+y} \mathrm{O}_{3-y}$ is an oxyhydride having a layered perovskite $\left(\mathrm{K}_{2} \mathrm{NiF}_{4}\right.$-type) structure that can act as a hydride ion conductor and $\mathrm{Ba}_{2} \mathrm{ScHO}_{3}$, with the same crystal structure, is also a hydride ion conductor. In the former compound, hydride ions occupy equatorial anion sites, while these ions are located at apical anion sites in $\mathrm{Ba}_{2} \mathrm{ScHO}_{3}$ and likely diffuse through rock-salt layers. However, the specific diffusion mechanism associated with the ionic conductivity of $\mathrm{Ba}_{2} \mathrm{ScHO}_{3}$ has not yet been elucidated. In the present study, the point defect formation energies and anionic conduction mechanisms of $\mathrm{Ba}_{2} \mathrm{ScHO}_{3}$ were systematically analyzed using first-principles calculations. The results show that hydride ion rather than oxide ion defects tend to form preferentially in $\mathrm{Ba}_{2} \mathrm{ScHO}_{3}$. The migration energies associated with vacancy, interstitial
\end{abstract}


and interstitialcy mechanisms were evaluated, and vacancy and interstitialcy-based hydride ion diffusion processes were found to have the lowest activation energies.

\section{Introduction}

Hydride ions have monovalent formal charges and are extremely light; hence they have attracted attention as rapid-conducting ionic charge carriers. As an example, several metal hydrides and oxyhydrides, such as $\mathrm{AeH}_{2}(\mathrm{Ae}=\mathrm{Ca}, \mathrm{Sr}, \mathrm{Ba}){ }^{1-3}$ and $\mathrm{LaH}_{3-2 \mathrm{x}} \mathrm{O}_{\mathrm{x}},{ }^{4}$ have been found to function as hydride ion conductors. The mobility of hydride ions in compounds with perovskite-type structures, such as acceptor-doped $\mathrm{SrTiO}_{3}{ }^{5-7}$ and $\mathrm{LaSrCoO}_{3} \mathrm{H}_{0.7}\left(\mathrm{~K}_{2} \mathrm{NiF}_{4}\right.$-type $){ }^{8}$ have also been studied. Kobayashi et al. reported that $\mathrm{La}_{2-\mathrm{x}-\mathrm{y}} \mathrm{Sr}_{\mathrm{x}+\mathrm{y}} \mathrm{LiH}_{1-\mathrm{x}+\mathrm{y}} \mathrm{O}_{3-\mathrm{y}}(0 \leq \mathrm{x}<1,0 \leq \mathrm{y} \leq 2)$, an oxyhydride series with $\mathrm{K}_{2} \mathrm{NiF}_{4}$-type layered perovskite structures, exhibits hydride ion conductivity. ${ }^{9}$ The ionic conduction mechanism in this series of compounds has been studied using first-principles calculations, and it has been suggested that the diffusion of hydride ions primarily proceeds via vacancies at equatorial anion sites in the perovskite layers. ${ }^{10-13}$ Recently, $\mathrm{Ba}_{2} \mathrm{ScHO}_{3}$ was reported as a new hydride ion conductor having the same $\mathrm{K}_{2} \mathrm{NiF}_{4}$-type structure but differing from $\mathrm{La}_{2-x-y} \mathrm{Sr}_{x+y} \mathrm{LiH}_{1-\mathrm{x}+\mathrm{y}} \mathrm{O}_{3-\mathrm{y}}$ in that the hydride ions occupy only apical rather than equatorial sites. ${ }^{14}$ As a consequence, hydride ions are believed to have the capacity to migrate through the rock-salt layers in this compound. However, the point defect species responsible for hydride ion conduction in $\mathrm{Ba}_{2} \mathrm{ScHO}_{3}$ and the associated conduction mechanisms have not yet been clarified. In the present work, we systematically evaluated the formation energies for various point defects using 
first-principles calculations, and attempted to identify preferentially generated anionic point defect species. The results were used to examine the ionic conduction mechanism in $\mathrm{Ba}_{2} \mathrm{ScHO}_{3}$, employing a transition state search method combined with the first-principles calculations.

\section{Methods}

First-principles total energy calculations were performed using the projector augmented wave (PAW) method ${ }^{15,16}$ as implemented in the VASP code. ${ }^{17-19}$ Details of the total energy calculation conditions can be found in our previous work. ${ }^{14}$ In the present study, supercell models were constructed to examine the formation energies and migration barriers of point defects in $\mathrm{Ba}_{2} \mathrm{ScHO}_{3}$. Our previous research ${ }^{14}$ established that the most stable configuration of $\mathrm{Ba}_{2} \mathrm{ScHO}_{3}$ is based on the alternate stacking of $\mathrm{Ba}_{2} \mathrm{H}_{2}(\mathrm{BH})$ and $\mathrm{Ba}_{2} \mathrm{O}_{2}(\mathrm{BO})$ rock-salt layers with $\mathrm{ScO}_{2}$ layers along the $c$-axis, as shown in Figure 1. Therefore, this fully ordered configuration was adopted as the initial structure for a defective $\mathrm{Ba}_{2} \mathrm{ScHO}_{3}$ system. The supercell model used in this work incorporated $2 \times 2 \times 1$ conventional unit cells of $\mathrm{Ba}_{2} \mathrm{ScHO}_{3}$. All internal atomic positions in the supercell model were relaxed with fixing the supercell size until the residual forces acting on atoms become lower than $0.02 \mathrm{eV} / \AA$. The supercell calculations were performed by sampling one $\boldsymbol{k}$-point at $\left(1 / 4 \frac{1}{4} 1 / 4\right)$ in the Brillouin zone with a cut-off energy of $400 \mathrm{eV}$ for plane-wave basis sets.

Each point defect formation energy was calculated as ${ }^{20}$

$$
E_{\mathrm{f}}\left(D^{q}\right)=\left\{E_{\text {sup }}^{\text {def }}\left(D^{q}\right)+E_{\text {corr }}^{\text {def }}\left(D^{q}\right)\right\}-E_{\text {sup }}^{\text {perfect }}-\sum_{i} \Delta n_{i} \mu_{i}+q\left(\varepsilon_{\mathrm{VBM}}+\Delta \varepsilon_{\mathrm{f}}\right)
$$


where $E_{\text {sup }}^{\text {perfect }}$ and $E_{\text {sup }}^{\text {def }}\left(D^{q}\right)$ are the total energies of a perfect supercell and a defective supercell including a point defect, $D$, with a charge $q$, respectively, and $E_{\text {corr }}^{\text {def }}\left(D^{q}\right)$ is an energy correction term associated with the image charge of the defective supercell. The energies determined for the charged defect supercells were corrected using the extended Freysoldt-Neugebauer-Van de Walle scheme developed by Kumagai and Oba, ${ }^{20-22}$ while the dielectric tensors were calculated using the linear response method. ${ }^{23}$ The ion-clamped dielectric tensors had calculated values of $\varepsilon_{\mathrm{xx}}^{\mathrm{el}}=\varepsilon_{\mathrm{yy}}^{\mathrm{el}}=$ 4.33 and $\varepsilon_{\mathrm{zz}}^{\mathrm{el}}=4.32$ and the ionic contributions were $\varepsilon_{\mathrm{xx}}^{\mathrm{ion}}=\varepsilon_{\mathrm{yy}}^{\mathrm{ion}}=16.89$ and $\varepsilon_{\mathrm{zz}}^{\mathrm{ion}}=10.61$. The terms $\mu_{i}$ and $\Delta n_{i}$ in Equation 1 represent the chemical potential of atom $i$ and the difference in the atom $i$ quantities between the defective and perfect supercells, respectively. The latter term is positive or negative in the case of interstitial and vacancy defects, respectively. The term $\varepsilon_{\mathrm{VBM}}$ represents the energy level of the valence band maximum (VBM), while $\Delta \varepsilon_{\mathrm{f}}$ corresponds to the Fermi energy as measured from the $\varepsilon_{\mathrm{VBM}}$. The $\mathrm{VBM}$ of the $\mathrm{Ba}_{2} \mathrm{ScHO}_{3}$ supercell used in this study was found to be located at the $\Gamma$ point in the Brillouin zone of the supercell, which differed from the sampled $\boldsymbol{k}$-point in our supercell calculations for point defects. Thus, the value of $\varepsilon_{\mathrm{VBM}}$ was calculated using the equation ${ }^{24}$

$$
\varepsilon_{\mathrm{VBM}}=E_{\text {sup }}^{\text {perfect }}-E_{\text {sup }}^{\text {perfect }}(q=+1)+\delta_{\mathrm{VBM}}
$$

where $E_{\text {sup }}^{\text {perfect }}(q=+1)$ is the total energy of a perfect supercell with a positive charge induced by the removal of one electron, and $\delta_{\mathrm{VBM}}$ is the energy difference in the VBM eigenvalues for the $\Gamma$ point and the $\boldsymbol{k}$ point of $(1 / 41 / 41 / 4)$. The term $\delta_{\mathrm{VBM}}$ is equal to $\varepsilon_{\mathrm{VBM}}(\boldsymbol{k}=\Gamma)-\varepsilon_{\mathrm{VBM}}(\boldsymbol{k}=(1 / 41 / 41 / 4))$ 
and had a value of $0.052 \mathrm{eV}$ in this study.

The chemical potentials values, $\mu_{i}$, were determined based on phase-equilibrium conditions and assuming that $\mathrm{Ba}_{2} \mathrm{ScHO}_{3}$ was in equilibrium with $\mathrm{BaO}, \mathrm{BaH}_{2}$ and atmospheric $\mathrm{H}_{2}$. Under these conditions, the total energies of the coexisting phases and chemical potentials were related as

$$
\left\{\begin{array}{rl}
E\left(\mathrm{Ba}_{2} \mathrm{ScHO}_{3}\right) & =2 \mu_{\mathrm{Ba}}+\mu_{\mathrm{Sc}}+\mu_{\mathrm{H}}+3 \mu_{\mathrm{O}} \\
E(\mathrm{BaO}) & =\mu_{\mathrm{Ba}}+\mu_{\mathrm{O}} \\
E\left(\mathrm{BaH}_{2}\right) & =\mu_{\mathrm{Ba}}+2 \mu_{\mathrm{H}}
\end{array} .\right.
$$

In this manner, unique chemical potentials could be obtained from the total energies of $\mathrm{Ba}_{2} \mathrm{ScHO}_{3}$, $\mathrm{BaO}, \mathrm{BaH}_{2}$ and $\mathrm{H}_{2}(\mathrm{~g})$. Assuming that $\mathrm{H}_{2}(\mathrm{~g})$ behaves as an ideal gas, the value of $\mu_{\mathrm{H}_{2}}$ at a specific temperature, $T$, and partial pressure, $p$, is given by ${ }^{25}$

$$
\mu_{\mathrm{H}_{2}}(T, p)=E_{\mathrm{H}_{2}}^{\mathrm{DFT}}+\Delta H_{\mathrm{H}_{2}}\left(T, p^{0}\right)-T S_{\mathrm{H}_{2}}\left(T, p^{0}\right)+k_{\mathrm{B}} T \ln \frac{p}{p^{0}}
$$

where $E_{\mathrm{H}_{2}}^{\text {DFT }}$ is the total energy of an $\mathrm{H}_{2}$ molecule at $0 \mathrm{~K}$ as determined using first-principles calculations. The thermodynamics parameters involved in this calculation, including the temperature dependence of enthalpy $\Delta H_{\mathrm{H}_{2}}\left(T, p^{0}\right)$ measured from $0 \mathrm{~K}$, the entropy $S_{\mathrm{H}_{2}}\left(T, p^{0}\right)$ at temperature $T$, and the standard state pressure, $p^{0}$, were taken from the literature. ${ }^{26}$

The vacancy, interstitial and substitutional anion site mixing defects identified in this work are summarized in Table $\mathrm{S} 1$. The $\mathrm{Ba}$ and $\mathrm{O}$ sites could be differentiated into two types according to the symmetry of the model shown in Figure 1 . These comprised $\mathrm{O}$ sites that were apical $\left(\mathrm{O}_{\mathrm{ap}}\right)$ or equatorial $\left(\mathrm{O}_{\mathrm{eq}}\right)$ and $\mathrm{Ba}$ sites in the $\mathrm{BH}$ and $\mathrm{BO}$ layers referred to as $\mathrm{Ba}$ BH and $\mathrm{Ba}$ Bo sites, respectively. This work also considered two types of interstitial sites in the rock-salt layers. Similar to the Ba sites, 
these interstitial sites could be categorized according to their locations. Specifically, interstitial defects of $\mathrm{X}$ with charge $q$ in the $\mathrm{BH}$ and $\mathrm{BO}$ layers were termed $\mathrm{X}_{\mathrm{i}_{\mathrm{BH}}}^{q}$ ad $\mathrm{X}_{\mathrm{i}_{\mathrm{BO}}}^{q}$, respectively. Diagrams of these interstitial sites are provided in Figure S1. The minimum energy paths for the migrations of $\mathrm{O}^{2-}$ and $\mathrm{H}^{-}$defects were identified using nudged elastic band methods, ${ }^{27}$ and vacancy, interstitial and interstitialcy mechanisms were investigated.

\section{Results and Discussion}

\subsection{Electronic Structures}

Before analyzing point defects, we investigated the electronic structures of $\mathrm{Ba}_{2} \mathrm{ScHO}_{3}$, and the resulting electronic total and partial density of states (DOSs) that were calculated are shown in

Figure 2. The calculated total DOS indicates that $\mathrm{Ba}_{2} \mathrm{ScHO}_{3}$ has a wide band gap of $3.7 \mathrm{eV}$, which is preferable for a solid electrolyte acting as an insulator. The VBM was found to be primarily composed of $\mathrm{O} 2 \mathrm{p}$ and $\mathrm{H}$ 1s orbitals, while the conduction band minimum (CBM) comprised $\mathrm{Sc} 3 \mathrm{~d}$ and $\mathrm{Ba} 6 \mathrm{~s} / 5 \mathrm{p}$ orbitals.

\subsection{Formation Energies of Point Defects}

Figure 3 plots the formation energies of the point defects as functions of $\Delta \varepsilon_{\mathrm{f}}$. Note that, when calculating $\mu_{\mathrm{H}}$ values, the partial pressure and the temperature of the $\mathrm{H}_{2}$ gas phase were set to $1 \mathrm{~atm}$ 
and $600 \mathrm{~K}$, respectively. These atmospheric conditions matched those applied during the measurements of the ionic conductivity of $\mathrm{Ba}_{2} \mathrm{ScHO}_{3}$ in our previous work. ${ }^{14}$ In this figure, each straight line corresponds to a specific charge state for a particular point defect. In addition, positive and negative slopes indicate donor-type (positively charged) and acceptor-type (negatively charged) defects, respectively, while higher straight line slopes are associated with greater $|q|$ values for the corresponding defects. The inflection points of the lines indicate the energy values for the thermal transitions between charge states. ${ }^{28}$ Assuming charge neutrality, $\Delta \varepsilon_{\mathrm{F}}$ for the band gap at equilibrium can be determined from the intersection of the lines for the positively and negatively charged defects having the lowest formation energies. On this basis, Figure 3 demonstrates that the most stable defect combination associated with charge neutrality consisted of site mixing defects based on hydride and oxide ions: $\mathrm{H}_{\mathrm{O}_{\mathrm{eq}}}^{-}$and $\mathrm{O}_{\mathrm{H}}^{\prime}$. In this scenario, $\Delta \varepsilon_{\mathrm{F}}$ was located approximately $2.19 \mathrm{eV}$ above the VBM.

Table 1 summarizes the formation energies of anionic point defects with formal charges (i.e., fully ionized) states for a $\Delta \varepsilon_{\mathrm{F}}$ value of $2.19 \mathrm{eV}$, as discussed above. Partially ionized or neutral charge states were also included in Table 1 if these states had lower formation energy values and were more stable relative to the fully ionized states. Judging from the formation energies, the most important defects were evidently $\mathrm{H}_{\mathrm{O}_{\mathrm{eq}}}$ and $\mathrm{O}_{\mathrm{H}}^{\prime}$, which both had a formation energy of $0.43 \mathrm{eV}$. It should also be noted that the site mixing defect for a hydride ion at an $\mathrm{O}_{\mathrm{ap}}$ site, $\mathrm{H}_{\mathrm{O}_{\mathrm{ap}}}$, had a comparable formation energy of $0.55 \mathrm{eV}$. Figure S2 presents the optimized atomic structures near the $\mathrm{H}_{\mathrm{O}_{\mathrm{ap}}}^{\cdot}, \mathrm{H}_{\mathrm{O}_{\mathrm{eq}}}^{\cdot}$ and $\mathrm{O}_{\mathrm{H}}^{\prime}$ site-mixing anion defects, while the differences in bond lengths between the 
initial (perfect) and optimized (defective) structures are summarized in Tables S2 to S4. Compared with the bond lengths between site-mixing $\mathrm{O}^{2-}$ ions and cations, those between site-mixing $\mathrm{H}^{-}$ions and cations were found to be longer, while the substitution of $\mathrm{H}^{-}$for $\mathrm{O}^{2-}$ ions decreased the distances to the surrounding anions. These effects can likely be attributed to the weaker Coulomb interactions between $\mathrm{H}^{-}$sites and surrounding ions compared with those between $\mathrm{O}^{2-}$ sites and surrounding ions.

After the site mixing defects, the hydride ion vacancies, $v_{\mathrm{H}}^{\cdot}$ and $v_{\mathrm{H}}^{\times}$, and interstitial hydride ions in the $\mathrm{BH}$ layer, $\mathrm{H}_{\mathrm{i}_{\mathrm{BH}}}^{\prime}$, were the next major defects. Our calculations also established that all point defects related to oxide ions other than $\mathrm{O}_{\mathrm{H}}^{\prime}$ sites had formation energies in excess of $1 \mathrm{eV}$, and that oxide ion defects were less likely to form than hydride ion defects. Among the vacancies and interstitial defects associated with oxide ions, vacancies at the equatorial sites, $v_{\mathrm{O}_{\text {eq }}}$, had the lowest formation energy of $1.32 \mathrm{eV}$. This value was 0.60 and $0.53 \mathrm{eV}$ greater than those for $v_{\mathrm{H}}^{\cdot}$ and $\mathrm{H}_{\mathrm{i}_{\mathrm{BH}}}^{\prime}$ sites, respectively. Oxide ion interstitials were found to have formation energies higher than $2 \mathrm{eV}$, meaning that in contrast to interstitial hydride ions such as $\mathrm{H}_{\mathrm{i}_{\mathrm{BH}}^{\prime}}^{\prime}$, the oxide ion interstitials formed less readily. Figure $\mathrm{S} 3$ provides the optimized atomic structures in the vicinity of the $v_{\mathrm{H}}^{\cdot}, v_{\mathrm{O}_{\mathrm{ap}}}^{\cdot}$ and $v_{\mathrm{O}_{\text {eq }}}$ vacancy defects. The differences in bond lengths between the initial (perfect) and optimized (defective) structures are summarized in Tables S5 to S7. The bond lengths around vacancies in the optimized structures were calculated as the distances between the original regular sites where vacancies were introduced and the ions surrounding the vacancies. Following the formation of anion vacancies, the surrounding anions (cations) moved toward (away from) the vacancy sites because the 
attractive (repulsive) interactions with the missing anions were no longer present. The optimized atomic structures in the vicinities of the $\mathrm{H}_{\mathrm{i}_{\mathrm{BH}}}^{\prime}, \mathrm{H}_{\mathrm{i}_{\mathrm{BO}}}^{\prime}, \mathrm{O}_{\mathrm{i}_{\mathrm{BO}}}^{\prime \prime}$ and $\mathrm{O}_{\mathrm{i}_{\mathrm{BH}}}^{\prime \prime}$ interstitial hydride and oxide ion defects are shown in Figure S4, while data regarding the local bonds near the interstitial defects are presented in Tables S8 to S11. Figure S4 demonstrates clear distortion of the anions around the interstitials. Interestingly, the bond lengths between the interstitial anions and their nearest neighboring $\mathrm{Ba}$ ions were shortened following relaxation even though the interstitial sites represented narrower spaces than the regular anion sites. This effect can likely be ascribed to the bonding states between the $\mathrm{Ba}^{2+}$ ions and anions. The magnitudes of the anion displacements around $\mathrm{O}_{\mathrm{i}_{\mathrm{BO}}}^{\prime \prime}$ and $\mathrm{O}_{\mathrm{i}_{\mathrm{BH}}}^{\prime \prime}$ sites were also determined to be larger than those around $\mathrm{H}_{\mathrm{i}_{\mathrm{BO}}}^{\prime}$ and $\mathrm{H}_{\mathrm{i}_{\mathrm{BH}}}^{\prime}$ sites, and this result is attributed to the stronger repulsive interactions with $\mathrm{O}^{2-}$ ions relative to those with $\mathrm{H}^{-}$ ions. As shown in Table 1, although the intralayer distance for $\mathrm{Ba}_{2} \mathrm{H}_{2}$ layers of $2.270 \AA$ was less than that for $\mathrm{Ba}_{2} \mathrm{O}_{2}$ layers $(2.476 \AA)$ in the fully ordered $\mathrm{Ba}_{2} \mathrm{ScHO}_{3}$ structure, the formation energies of $\mathrm{H}_{\mathrm{i}_{\mathrm{BH}}}^{\prime}$ and $\mathrm{O}_{\mathrm{i}_{\mathrm{BH}}}^{\prime \prime}$ sites were less than those of $\mathrm{H}_{\mathrm{i}_{\mathrm{BO}}}^{\prime}$ and $\mathrm{O}_{\mathrm{i}_{\mathrm{BO}}}^{\prime \prime}$ sites, respectively. This result also suggests that the energy states of the interstitial anion defects were primarily determined by repulsive interactions with surrounding anions.

The formation energies for cation point defects are summarized in Table S12, and can be seen to all exceed $2 \mathrm{eV}$. As such, fewer cation defects than anion defects would be expected to form. Based on this result, we believe that the effect of the cation defects on the formation and diffusion behavior of the anion defects was negligible. 


\subsection{Migration Energy}

As discussed above, this work assessed three migration processes: vacancy, interstitial and interstitialcy. In the interstitialcy mechanism, an interstitial ion moved toward a neighboring regular site while an ion originally located at the regular site migrated to another interstitial site. This process is also known as cooperative or concerted motion ${ }^{29,30}$ because it involves the simultaneous movement of multiple ions. The interstitialcy modes for hydride and oxide ions are herein expressed as $\left(\mathrm{H}_{\mathrm{i}}^{\prime} \mathrm{H}_{\mathrm{H}}^{\times}\right)$and $\left(\mathrm{O}_{\mathrm{i}}^{\prime \prime} \mathrm{O}_{\mathrm{O}}^{\times}\right)$, respectively, in order to distinguish them from the interstitial modes. As noted previously, both fully ionized and partially ionized states, such as $v_{\mathrm{O}_{\mathrm{eq}}}, v_{\mathrm{O}_{\mathrm{ap}}}$ and $\mathrm{O}_{\mathrm{i}_{\mathrm{BH}}}^{\prime}$, were present as major defects under the phase equilibrium conditions shown in Figure 3. Thus, calculations to identify transition states were also performed for the defects associated with partially ionized states.

Figure 4 shows the energy profiles calculated for the three kinds of migration processes. Neutral hydride ion vacancies, $v_{\mathrm{H}}^{\times}$, and partially ionized oxide ion vacancies, $v_{\mathrm{O}_{\mathrm{eq}}}$ and $v_{\mathrm{O}_{\mathrm{ap}}}$, were determined to have larger energy barriers than the corresponding fully ionized states $v_{\mathrm{H}}^{\cdot}, \quad v_{\mathrm{O}_{\mathrm{eq}}}$ and $v_{\mathrm{O}_{\mathrm{ap}}}^{.}$. The migration energy barrier for $\mathrm{O}_{\mathrm{i}_{\mathrm{BH}}}^{\prime}$ was also found to be slightly higher than that for $\mathrm{O}_{\mathrm{i}_{\mathrm{BH}}}^{\prime \prime}$ and so it can be concluded that partially ionized defects were less mobile than fully ionized ones. Similar trends in the dynamics of point defects related to the migration behaviors of hydride ion vacancies in $\mathrm{AeH}_{2}(\mathrm{Ae}=\mathrm{Ca}, \mathrm{Sr}, \mathrm{Ba})$ systems have also been reported. ${ }^{31}$ 
At this point, it is helpful to focus on formal charge defects. Compared with $v_{\mathrm{O}_{\mathrm{ap}}}$ defects, $v_{\mathrm{O}_{\mathrm{eq}}}$ defects were determined to have a lower migration energy of $0.69 \mathrm{eV}$, while $v_{\mathrm{H}}$ vacancies had the lowest migration barrier of $0.45 \mathrm{eV}$. The trajectories of the $v_{\mathrm{H}}^{\cdot}$ and $v_{\mathrm{O}_{\text {eq }}}$ migration processes are illustrated in

Figure 5 and 6, respectively, and that of $v_{\mathrm{O}_{\mathrm{ap}}}^{.}$migration is provided in Figure $\mathrm{S} 5$ as a reference. In the case of the interstitial processes, the barriers associated with migration through the $\mathrm{BH}$ layers were found to be lower than those through the BO layers. Similar to the conclusions regarding the formation energies of interstitial defects, it appears that repulsive interactions with $\mathrm{H}^{-}$sites in the $\mathrm{BH}$ layers were weaker than those with $\mathrm{O}^{2-}$ in the $\mathrm{BO}$ layers. Among the interstitial processes, the barrier for $\mathrm{H}_{\mathrm{i}_{\mathrm{BH}}}^{\prime}$ migration was the lowest, at $0.86 \mathrm{eV}$, and the $\mathrm{H}_{\mathrm{i}_{\mathrm{BH}}}^{\prime}$ and $\mathrm{O}_{\mathrm{i}_{\mathrm{BO}}}^{\prime \prime}$ trajectories are shown in エラー! 参照元が見つかりません。 and S6, respectively. The data in Figure 4 also demonstrate that the interstitialcy processes involved lower migration barriers compared with the vacancy and interstitial processes, and the energies for the $\left(\mathrm{H}_{\mathrm{i}}^{\prime} \mathrm{H}_{\mathrm{H}}^{\times}\right)$and $\left(\mathrm{O}_{\mathrm{i}}^{\prime \prime} \mathrm{O}_{\mathrm{O}}^{\times}\right)$migrations were calculated to be 0.35 and $0.46 \mathrm{eV}$, respectively. $\mathrm{La}_{2} \mathrm{NiO}_{4+\delta}$ has the same $\mathrm{K}_{2} \mathrm{NiF}_{4}$ structure as $\mathrm{Ba}_{2} \mathrm{ScHO}_{3}$. The energy values for the migration of oxide ions via interstitialcy processes in the rock-salt layers of this compound as obtained from first principles calculations and as reported in the literature are $0.3^{32}$ and $0.46 \mathrm{eV},{ }^{33}$ both of which are comparable to our own values. It should be noted that energy barriers to the migration of hydride ions were lower than those for the migration of oxide ions in all 
mechanisms. Figure 6 shows the trajectories associated with the interstitialcy mechanisms involving $\mathrm{H}^{-}$and $\mathrm{O}^{2-}$.

\subsection{Activation Energies for Ionic Diffusion}

Previous studies ${ }^{14}$ determined the ionic conductivities of stoichiometric $\mathrm{Ba}_{2} \mathrm{ScHO}_{3}$ specimens without dopants, and in the present work we assumed that the ionic conductivity of undoped $\mathrm{Ba}_{2} \mathrm{ScHO}_{3}$ results from the formation of intrinsic defects. Within the intrinsic defect region of stoichiometric ionic crystals, the activation energy for ionic conductivity $\left(\Delta E_{\mathrm{a}}\right)$ can be expressed as the summation of the enthalpy of formation $\left(\Delta H_{\mathrm{f}}\right)$ and the migration enthalpy $\left(\Delta H_{\mathrm{m}}\right)$ of charge carrier defects. ${ }^{31,34}$ Accordingly, we calculated the $\Delta E_{\mathrm{a}}$ for each migration process from the corresponding formation and migration energies as obtained using first-principles calculations, with the results shown in Figure 7. From these data, it is evident that the $\Delta E_{\mathrm{a}}$ values for all the oxide ion conduction mechanisms exceeded $2 \mathrm{eV}$. Among these processes, the $v_{\mathrm{O}_{\mathrm{eq}}}^{.}$mechanism showed the lowest $\Delta E_{\mathrm{a}}$ of $2.28 \mathrm{eV}$. Compared with oxide ion conduction, the hydride ion conduction processes had smaller $\Delta E_{\mathrm{a}}$. In addition, the $\Delta E_{\mathrm{a}}$ values for the $v_{\mathrm{H}}^{\cdot}$ and $\left(\mathrm{H}_{\mathrm{i}}^{\prime} \mathrm{H}_{\mathrm{H}}^{\times}\right)$processes were similar and also the lowest among all the anionic migration processes studied herein. Specifically, these $\Delta E_{\mathrm{a}}$ were determined to be 1.17 and $1.15 \mathrm{eV}$ for $v_{\mathrm{H}}^{\circ}$ and $\left(\mathrm{H}_{\mathrm{i}}^{\prime} \mathrm{H}_{\mathrm{H}}^{\times}\right)$, respectively. Previous experimental trials under a $\mathrm{H}_{2}$ gas flow obtained a value of $0.92 \mathrm{eV}(89.2 \mathrm{~kJ} / \mathrm{mol})$ for the ionic conductivity of $\mathrm{Ba}_{2} \mathrm{ScHO}_{3},{ }^{14}$ which is similar to the values of $\Delta E_{\mathrm{a}}$ for $v_{\mathrm{H}}$ and $\left(\mathrm{H}_{\mathrm{i}}^{\prime} \mathrm{H}_{\mathrm{H}}^{\times}\right)$obtained in the present work. From these results, 
we can conclude that the ionic conductivity of $\mathrm{Ba}_{2} \mathrm{ScHO}_{3}$ appears to primarily originate from $\mathrm{H}^{-}$ diffusion rather than from $\mathrm{O}^{2-}$ diffusion.

This study examined the ionic conduction mechanisms in $\mathrm{Ba}_{2} \mathrm{ScHO}_{3}$ within the intrinsic defect region, based on a fully ordered anion sublattice model within the rock-salt layers, which was found to be the most stable configuration. In contrast, actual physical samples of $\mathrm{Ba}_{2} \mathrm{ScHO}_{3}$ that have been synthesized exhibit disordered $\mathrm{O}^{2-} / \mathrm{H}^{-}$configurations in the rock-salt layers. If a portion of the $\mathrm{O}^{2-}$ ions is located in the $\mathrm{BH}$ layers, the number of effective carriers for the $v_{\mathrm{H}}^{\circ}$ and $\left(\mathrm{H}_{\mathrm{i}}^{\prime} \mathrm{H}_{\mathrm{H}}^{\times}\right)$processes will be reduced. In addition, the presence of $\mathrm{O}^{2-}$ ions might affect the migration of $\mathrm{H}^{-}$ions. Specifically, because $\mathrm{O}^{2-}$ ions have a greater formal charge than $\mathrm{H}^{-}$ions, the coexistence of site-mixing $\mathrm{O}^{2-}$ ions in the $\mathrm{BH}$ layers would be expected to increase the migration energy of $\mathrm{H}^{-}$ions. Therefore, if a $\mathrm{K}_{2} \mathrm{NiF}_{4}$-type oxyhydride compound with a fully ordered anionic configuration in the rock-salt layers as the ground state can actually be synthesized, this material would be expected to show higher hydride ion conductivity than $\mathrm{Ba}_{2} \mathrm{ScHO}_{3}$. In fact, it has recently been reported that $\mathrm{Ba}_{2} \mathrm{YHO}_{3}$, which has the same $\mathrm{K}_{2} \mathrm{NiF}_{4}$-type structure along with fully ordered hydride ion layers, exhibits hydride ion conductivity superior to that of $\mathrm{Ba}_{2} \mathrm{ScHO}_{3}{ }^{35}$ Thus, optimizing the anion distribution is evidently an effective means of promoting the ionic conductivities of oxyhydride compounds.

\section{Conclusion}


In this work, the energies of point defect formation and migration for a defective supercell model of $\mathrm{Ba}_{2} \mathrm{ScHO}_{3}$ were systematically obtained using first-principles calculations. Our computational analyses quantitatively demonstrate that the ionic conductivity in the intrinsic defect region of stoichiometric $\mathrm{Ba}_{2} \mathrm{ScHO}_{3}$ without dopants is derived from hydride ion rather than oxide ion defects. Hydride ions are able to diffuse through the rock-salt layer structure by means of vacancies or interstitialcy mechanisms. Thus, introducing hydride ion vacancies or interstitial hydride ions into these rock-salt type $\mathrm{Ba}_{2} \mathrm{H}_{2}$ layers via extrinsic doping would be expected to greatly improve the hydride ion conductivity of $\mathrm{Ba}_{2} \mathrm{ScHO}_{3}$. Controlling the anion configurations and optimizing the ionic conduction pathways for hydride ions should therefore provide $\mathrm{K}_{2} \mathrm{NiF}_{4}$-type oxyhydrides with higher ionic conductivities.

\section{Acknowledgement}

This work was supported by the Scientific Research on Innovative Areas project (grant numbers JP16H06440, JP17H05492, JP18H05516 and JP19H04710) and by a Grant-in-Aid for Scientific

Research (B) (number JP20H02828) from JSPS KAKENHI.

\section{Reference}

$1 \quad$ M. C. Verbraeken, E. Suard and J. T. S. Irvine, Journal of Materials Chemistry, 2009, 19, 27662770 . 
M. C. Verbraeken, C. Cheung, E. Suard and J. T. S. Irvine, Nature Materials, 2015, 14, 95-100.

X. Zhang, X. Wang, Q. Wang, X. Ma, C. Liu, P. Li, C. Liu, Y. Han, Y. Ma and C. Gao, Physical Chemistry Chemical Physics, 2018, 20, 8917-8923.

K. Fukui, S. Iimura, T. Tada, S. Fujitsu, M. Sasase, H. Tamatsukuri, T. Honda, K. Ikeda, T. Otomo and H. Hosono, Nature Communications, 2019, 10, 1-8.

S. Steinsvik, Y. Larring and T. Norby, Solid State Ionics, 2001, 143, 103-116.

M. Widerøe, W. Münch, Y. Larring and T. Norby, Solid State Ionics, 2002, 154-155, 669-677.

M. Widerøe, R. Waser and T. Norby, Solid State Ionics, 2006, 177, 1469-1476.

C. A. Bridges, F. Fernandez-Alonso, J. P. Goff and M. J. Rosseinsky, Advanced Materials, 2006, 18, 3304-3308.

G. Kobayashi, Y. Hinuma, S. Matsuoka, A. Watanabe, M. Iqbal, M. Hirayama, M. Yonemura, T. Kamiyama, I. Tanaka and R. Kanno, Science, 2016, 351, 1314-1317.

X. Liu, T. S. Bjørheim and R. Haugsrud, Journal of Materials Chemistry A, 2018, 6, 1454-1461.

Ø. S. Fjellvåg, J. Armstrong, P. Vajeeston and A. O. Sjåstad, Journal of Physical Chemistry Letters, 2018, 9, 353-358.

Y. Iwasaki, N. Matsui, K. Suzuki, Y. Hinuma, M. Yonemura, G. Kobayashi, M. Hirayama, I. Tanaka and R. Kanno, Journal of Materials Chemistry A, 2018, 6, 23457-23463.

Q. Bai, X. He, Y. Zhu and Y. Mo, ACS Applied Energy Materials, 2018, 1, 1626-1634.

F. Takeiri, A. Watanabe, A. Kuwabara, H. Nawaz, N. I. P. Ayu, M. Yonemura, R. Kanno and G. Kobayashi, Inorganic Chemistry, 2019, 58, 4431-4436.

P. E. Blöchl, Physical Review B, 1994, 50, 17953-17979.

G. Kresse and D. Joubert, Physical Review B, 1999, 59, 1758-1775.

G. Kresse and J. Hafner, Physical Review B, 1993, 47, 558-561.

G. Kresse and J. Furthmüller, Computational Materials Science, 1996, 6, 15-50.

G. Kresse and J. Furthmüller, Physical Review B, 1996, 54, 11169-11186.

Y. Kumagai and F. Oba, Physical Review B, 2014, 89, 195205.

C. Freysoldt, J. Neugebauer and C. G. van de Walle, Physical Review Letters, 2009, 102, 1-4.

Y. Kumagai, L. A. Burton, A. Walsh and F. Oba, Physical Review Applied, 2016, 6, 1-14.

M. Gajdoš, K. Hummer, G. Kresse, J. Furthmüller and F. Bechstedt, Physical Review B Condensed Matter and Materials Physics, 2006, 73, 1-9.

T. Mattila and A. Zunger, Physical Review B, 1998, 58, 1367-1373.

K. Reuter and M. Scheffler, Physical Review B - Condensed Matter and Materials Physics, 2002, $65,1-11$.

M. W. Chase Jr, NIST-JANAF Thermochemical Tables, 4th edn, AIP publishing, New York, 1998.

G. Henkelman, B. P. Uberuaga and H. Jónsson, The Journal of Chemical Physics, 2000, 113, 9901.

S. Lany and A. Zunger, Physical Review B - Condensed Matter and Materials Physics, 2005, 72, $1-13$. 
X. He, Y. Zhu and Y. Mo, Nature Communications, 2017, 8, 1-7.

30 H. Li, N. L. Okamoto, T. Hatakeyama, Y. Kumagai, F. Oba and T. Ichitsubo, Advanced Energy Materials, 2018, 8, 1-8.

31 A. J. E. Rowberg, L. Weston and C. G. van de Walle, Chemistry of Materials, 2018, 30, 5878-5885.

32 S. Xu, R. Jacobs and D. Morgan, Chemistry of Materials, 2018, 30, 7166-7177.

33 Z. Du, Z. Zhang, A. Niemczyk, A. Olszewska, N. Chen, K. Świerczek and H. Zhao, Physical Chemistry Chemical Physics, 2018, 20, 21685-21692.

34 K. Funke, Science and Technology of Advanced Materials, 2013, 14, 043502.

35 H. Nawaz, F. Takeiri, A. Kuwabara, M. Yonemura and G. Kobayashi, Chemical Communications, 2020, 56, 10373-10376. 
Table 1. Formation energies of anionic point defects having formal charge states. Atmospheric pressure and temperature conditions are the same as those used to generate the data shown in Figure 3. In the case that a point defect with a different charge state from the formal charge state had a lower formation energy than that with the formal charge state, the point defect with the different charge state is included in parentheses.

\begin{tabular}{cccccc}
\hline \multicolumn{2}{c}{ Vacancy } & \multicolumn{2}{c}{ Interstitial } & \multicolumn{2}{c}{ Site mixing } \\
\hline$v_{\mathrm{H}}^{\prime}$ & $0.72 \mathrm{eV}$ & $\mathrm{H}_{\mathrm{i}_{\mathrm{BH}}}^{\prime}$ & $0.79 \mathrm{eV}$ & $\mathrm{H}_{\mathrm{O}_{\mathrm{ap}}}^{\prime}$ & $0.55 \mathrm{eV}$ \\
$\left(v_{\mathrm{H}}^{\times}\right.$ & $0.67 \mathrm{eV})$ & & & & \\
& & $\mathrm{H}_{\mathrm{i}_{\mathrm{BO}}}^{\prime}$ & $1.27 \mathrm{eV}$ & $\mathrm{H}_{\mathrm{O}_{\mathrm{eq}}}^{.}$ & $0.43 \mathrm{eV}$ \\
\hline$v_{\mathrm{O}_{\mathrm{ap}}}^{.}$ & $1.98 \mathrm{eV}$ & $\mathrm{O}_{\mathrm{i}_{\mathrm{BH}}^{\prime}}^{\prime \prime}$ & $2.18 \mathrm{eV}$ & $\mathrm{O}_{\mathrm{H}}^{\prime}$ & $0.43 \mathrm{eV}$ \\
$\left(v_{\mathrm{O}_{\mathrm{ap}}}^{\prime}\right.$ & $1.42 \mathrm{eV})$ & $\left(\mathrm{O}_{\mathrm{i}_{\mathrm{BH}}}^{\prime}\right.$ & $1.97 \mathrm{eV})$ & & \\
$v_{\mathrm{O}_{\mathrm{eq}}}^{.}$ & $1.59 \mathrm{eV}$ & $\mathrm{O}_{\mathrm{i}_{\mathrm{BO}}^{\prime \prime}}^{\prime \prime}$ & $2.98 \mathrm{eV}$ & & \\
$\left(v_{\mathrm{O}_{\mathrm{eq}}}^{\prime}\right.$ & $1.32 \mathrm{eV})$ & & & & \\
\hline
\end{tabular}




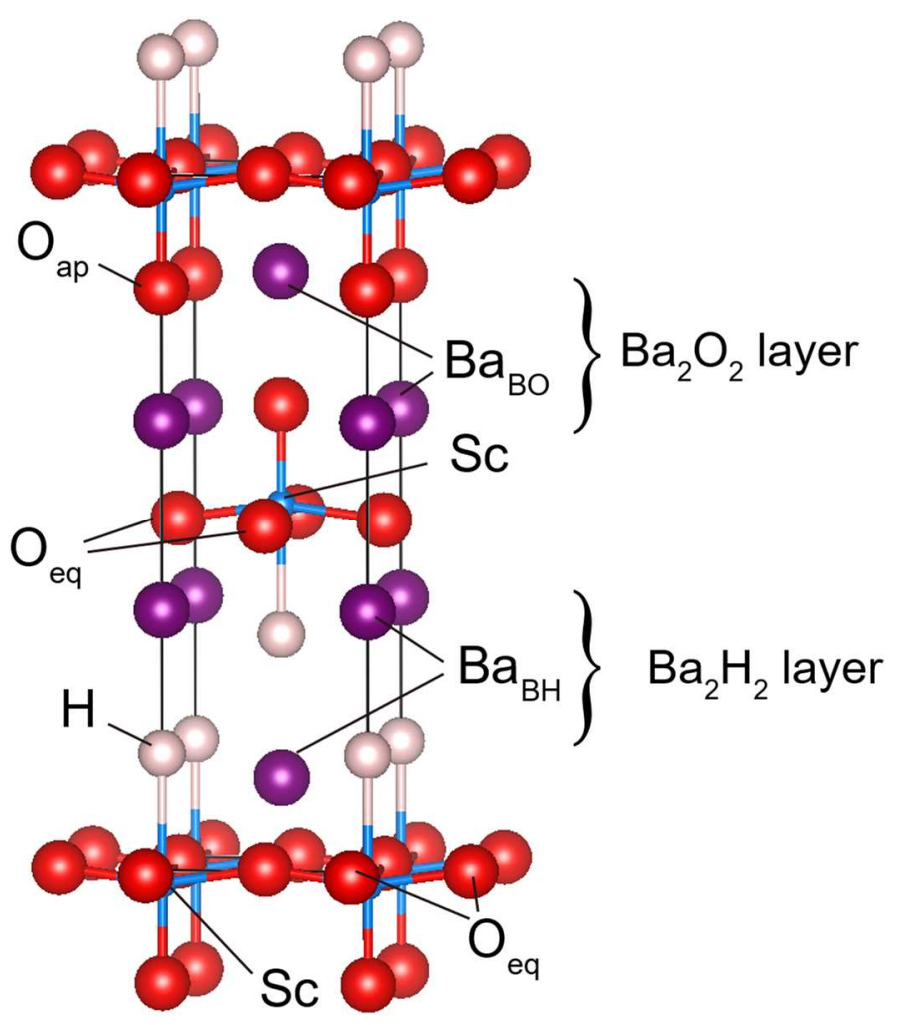

Figure 1. The initial structure of the ordered $\mathrm{Ba}_{2} \mathrm{ScHO}_{3}$ model used in this study. The $\mathrm{H}^{-} / \mathrm{O}^{2-}$ configuration at anion sites shown here was determined to be the most stable in a previous study. ${ }^{14}$ 

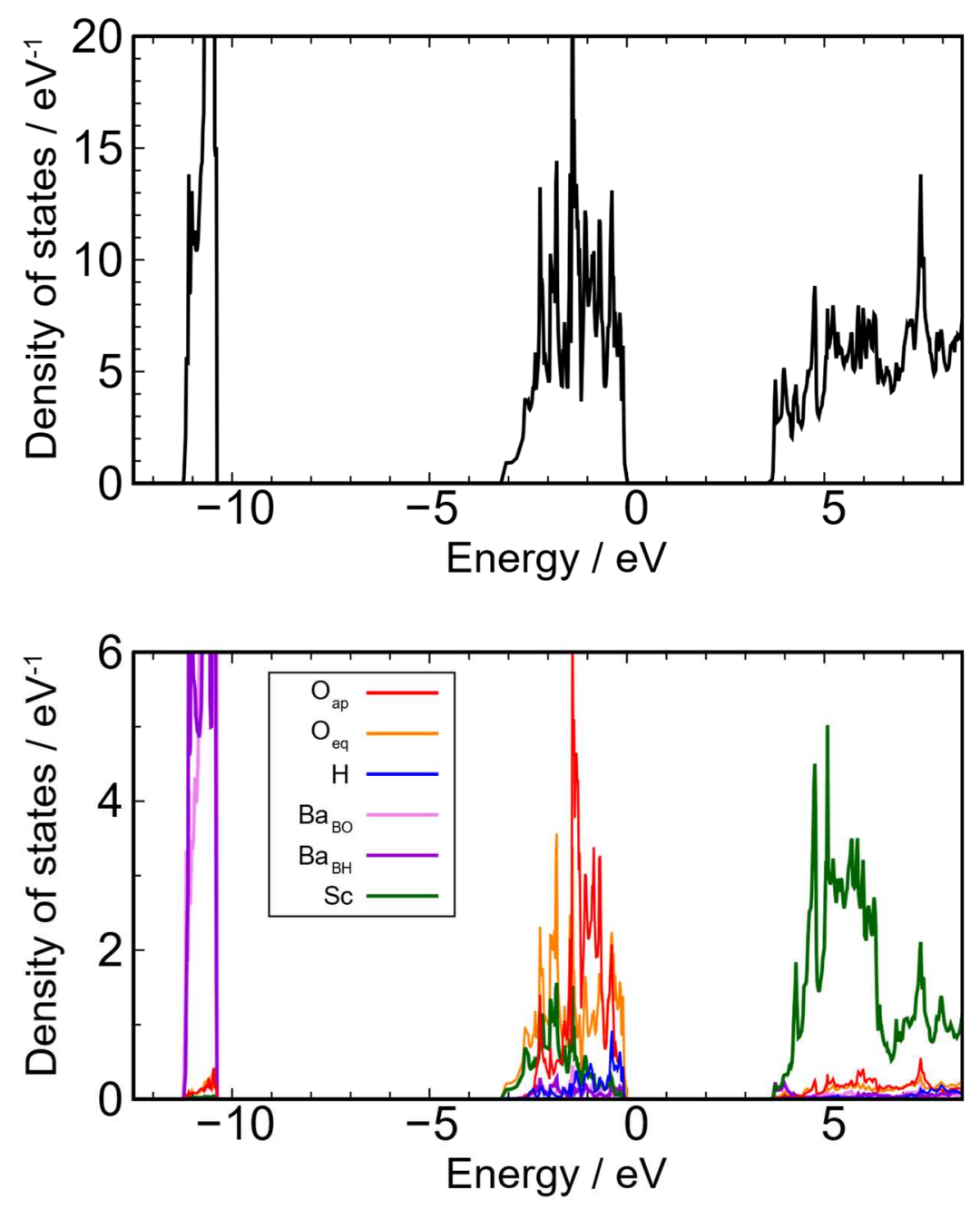

Figure 2. Calculated total and partial density of states for $\mathrm{Ba}_{2} \mathrm{ScHO}_{3}$. In the case of the horizontal axis, $0 \mathrm{eV}$ corresponds to the highest occupied energy level. 


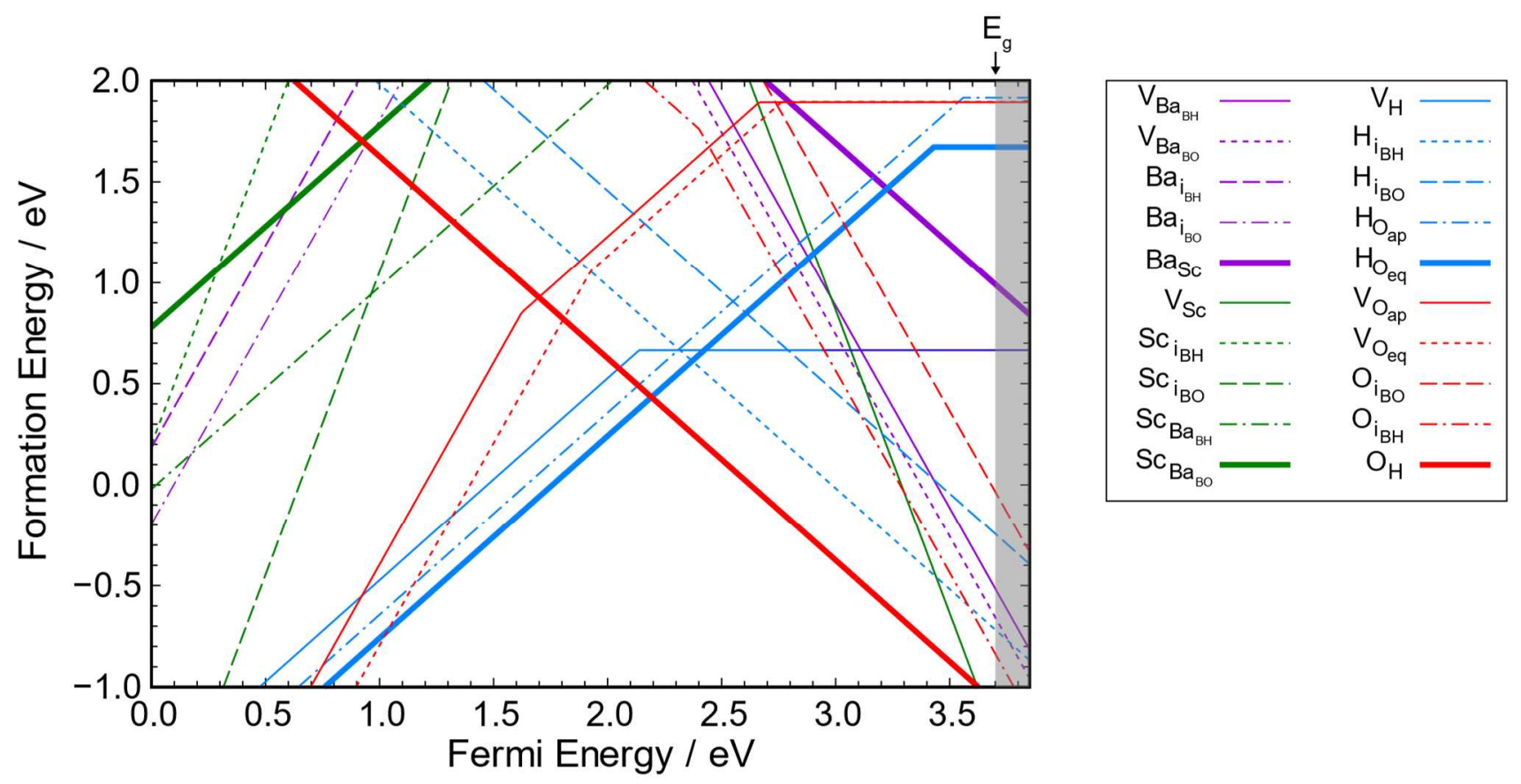

Figure 3. Plots of defect formation energies in $\mathrm{Ba}_{2} \mathrm{ScHO}_{3}$ against $\boldsymbol{\Delta} \boldsymbol{\varepsilon}_{\mathbf{f}}$. In the case of the horizontal axis, $0 \mathrm{eV}$ corresponds to the highest occupied energy level. The grey area in the graph indicate conduction band regions. 

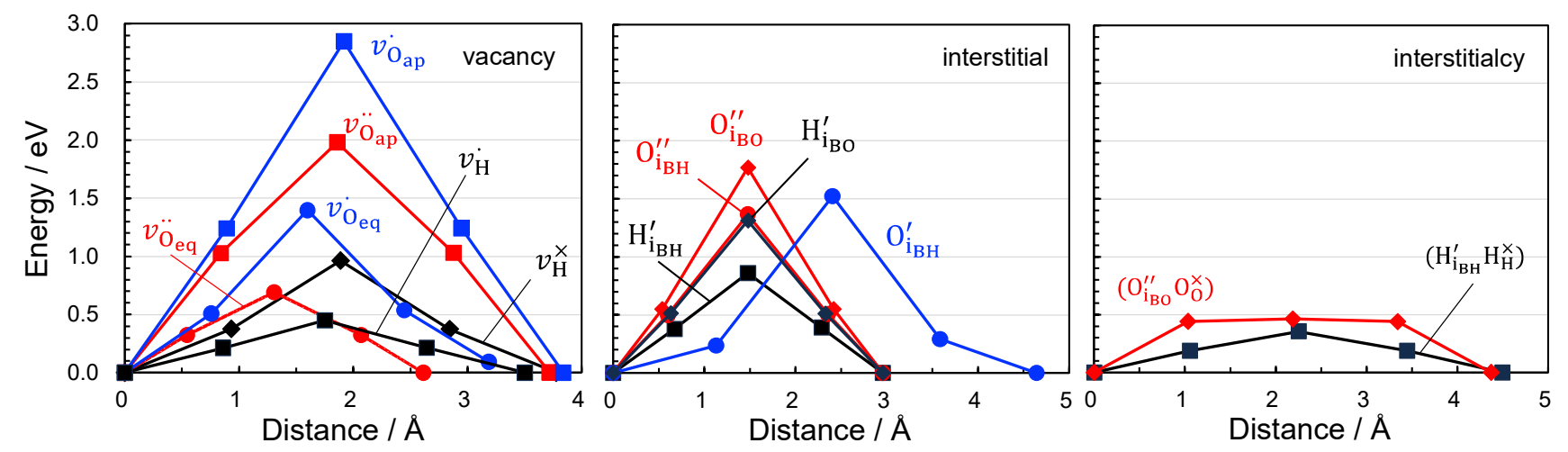

Figure 4. Energy profiles for the migration of oxide and hydride ions via (a) vacancy, (b) interstitial, and (c) interstitialcy mechanisms as determined from first-principles calculations combined with the NEB method. 
(a)

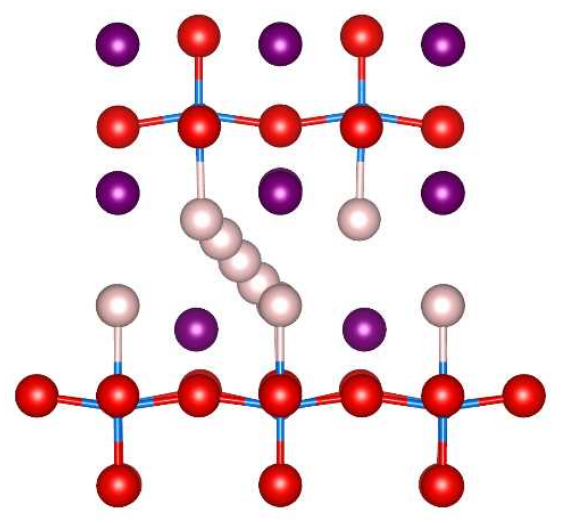

(b)

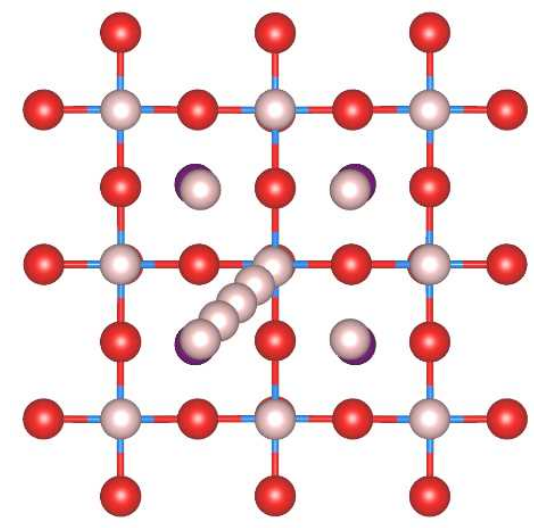

Figure 5. Trajectories of hydride ion migration based on the $\boldsymbol{v}_{\mathbf{H}}$ mechanisms as viewed from (a) the [100] and (b) the [001] direction.

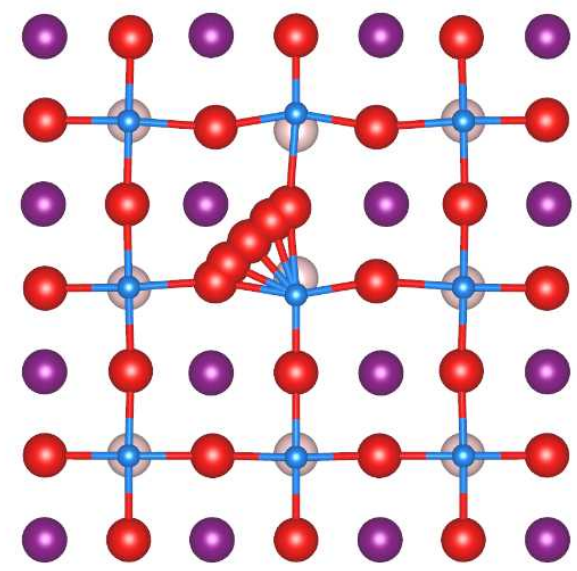

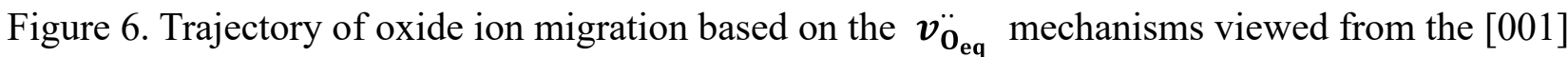
direction. 
(a)

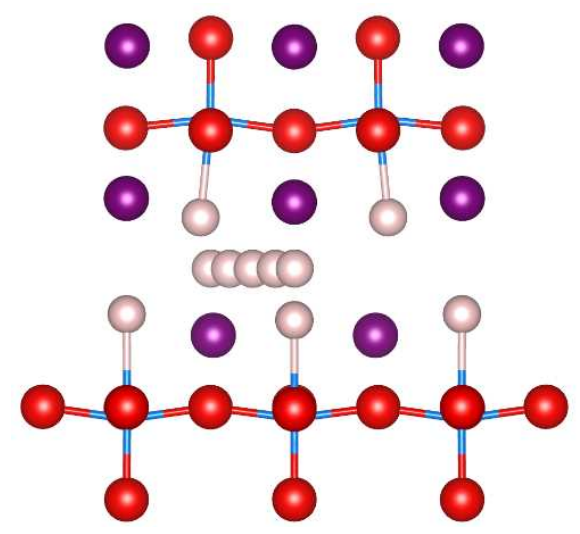

(b)

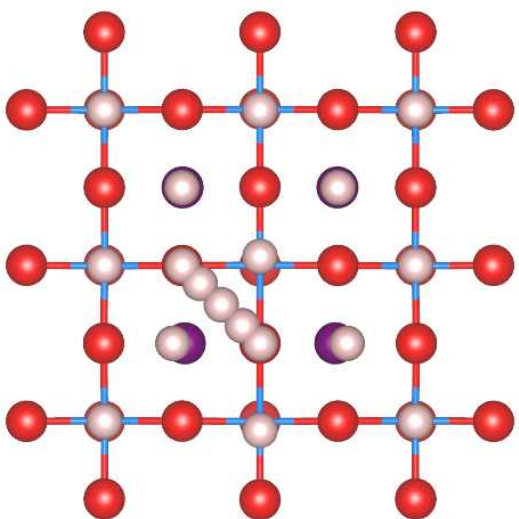

Figure 7. Trajectories of hydride ion migration based on the $\mathbf{H}_{\mathbf{i}_{\mathbf{B H}}}$ mechanisms as viewed from (a) the [100] and (b) the [001] direction. 
(a)

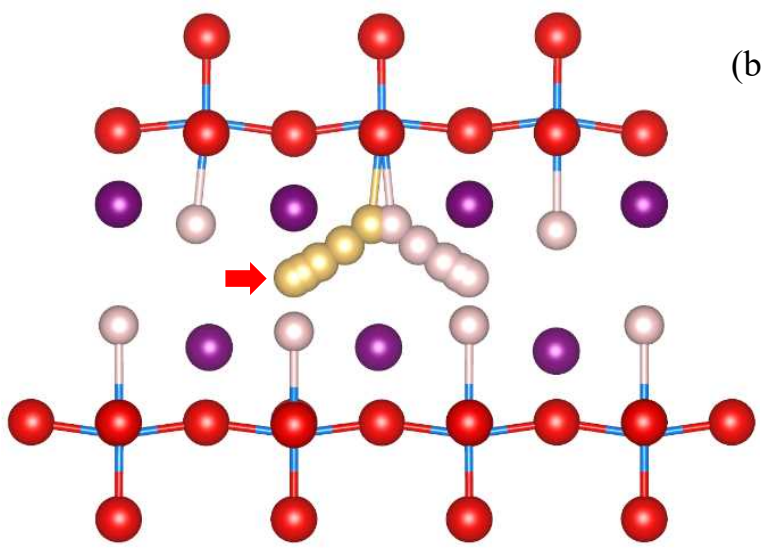

(b)

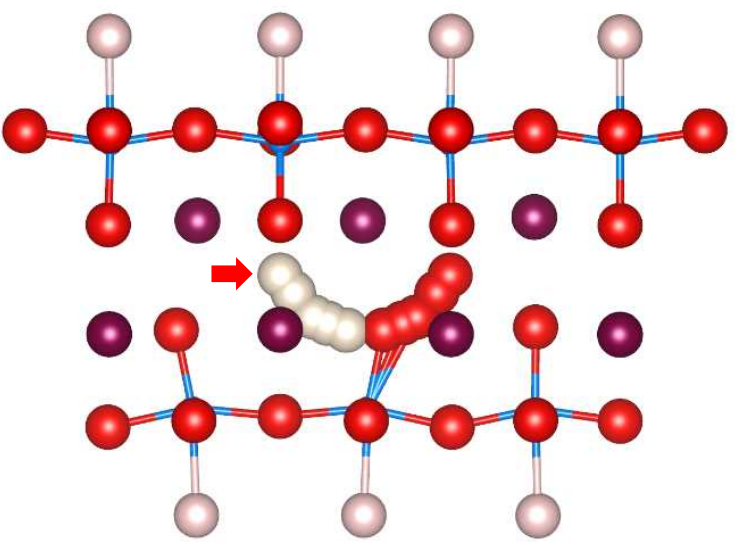

Figure 6. Trajectories of (a) hydride ion and (b) oxide ion migration by the $\left(\mathbf{H}_{\mathbf{i}_{\mathbf{B H}}^{\prime}}^{\prime} \mathbf{H}_{\mathbf{H}}^{\times}\right)$and $\left(\mathbf{O}_{\mathbf{i}_{\mathbf{B} \mathbf{0}}^{\prime \prime}}^{\prime \prime} \mathbf{O}_{\mathbf{0}}^{\times}\right)$mechanisms, respectively, as viewed from the [100] direction. Original interstitial defects are indicated by the red arrows. 


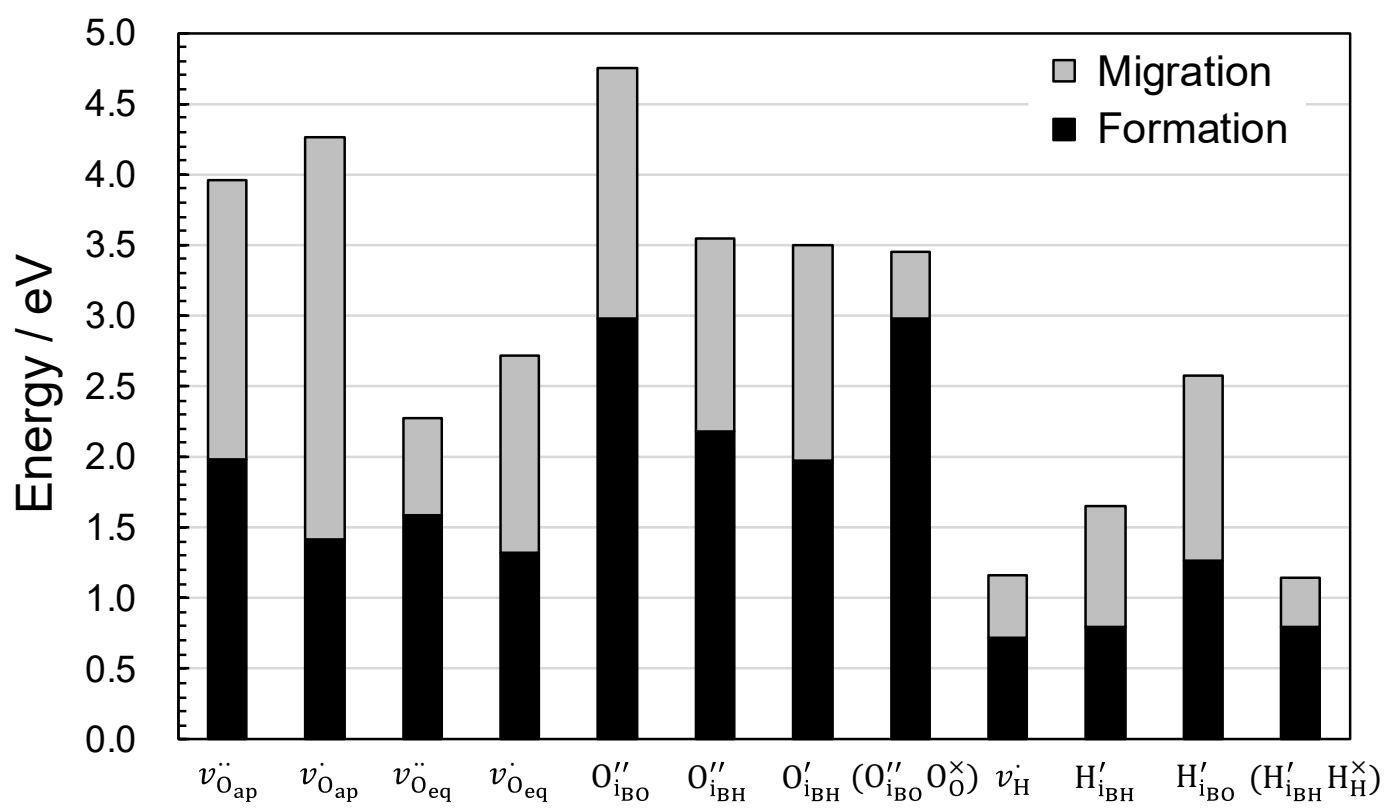

Figure 7. Ionic diffusion activation energies calculated assuming intrinsic defect formation behavior. 